\title{
Capital Turístico e as Teorias Sociais de Marx, Bourdieu e Putnam
}

\author{
Tourist Capital and the Social Theories of Marx, Bourdieu and Putnam
}

Capital Turística y las Teorías Sociales de Marx, Bourdieu y Putnam

Marcelo da Silva Taveira ${ }^{1}$

\begin{abstract}
Resumo
A finalidade dessa análise é promover o debate teórico-metodológico sobre as bases conceituais da construção de um novo conceito no campo do saber turístico, denominado de capital turístico. Tal assunto tem como intuito o aprofundamento empírico e teórico desse conceito, cuja inspiração deu-se a partir das teorias sociais de Karl Marx (capital econômico), Pierre Bourdieu (capital simbólico) e Robert Putnam (capital social). Nessa perspectiva, entende-se que o capital turístico é o legado econômico, social e simbólico proporcionado por fatores técnicos, científicos, informacionais, empresariais e públicos, com participação de organizações governamentais e não governamentais e das comunidades, materializado e desenvolvido em lugares apropriados pelo turismo articulados com os outros lugares. Entretanto, fez-se necessário uso da abordagem metodológica de natureza qualitativa e análise crítica para o processo reflexivo da discussão aqui posta. Assim, o conceito de capital turístico apresenta-se como mais uma contribuição teórica aos estudos e pesquisas para a melhor compreensão do fenômeno turístico no cenário contemporâneo.
\end{abstract}

Palavras-chave: Capital turístico; Capital econômico; Capital simbólico; Capital social.

\begin{abstract}
The purpose of this analysis is to promote theoretical and methodological debate on the conceptual bases of the construction of a new concept in tourist know of the field, called the tourist capital. This subject has as objective the empirical and theoretical study of this concept, whose inspiration was given from the social theories of Karl Marx (economic capital), Pierre Bourdieu (symbolic capital) and Robert Putnam (social capital). From this perspective, it is understood that the tourist capital this sense, the tourist capital is the economic, social and symbolic legacy provided by technical, scientific, informational, corporate and public factors with participation of governmental and nongovernmental organizations and communities, materialized and developed in appropriate places for tourism with articulated elsewhere. However, it was necessary to use the methodological approach of qualitative and critical analysis for the reflective process of discussion here put. Thus, the concept of tourist capital presents itself as another theoretical contribution to the study and research for a better understanding of the tourism phenomenon in the contemporary scene.
\end{abstract}

Keywords: Tourist capital; Economic capital; Symbolic capital; Social capital.

\footnotetext{
${ }^{1}$ Doutor em Ciências Sociais pela Universidade Federal do Rio Grande do Norte. Professor do Curso de Turismo do Departamento de Ciências Sociais e Humanas do Centro de Ensino Superior do Seridó da Universidade Federal do Rio Grande do Norte. Currais Novos, Brasil. E-mail: marceloturismo@yahoo.com.br
} 


\section{Resumen}

El propósito de este análisis es promover el debate teórico y metodológico sobre las bases conceptuales de la construcción de un nuevo concepto de conocimientos turística del campo, llamada la capital turística. Este tema tiene como objetivo el estudio empírico y teórico de este concepto, cuya inspiración fue dado de las teorías sociales de Karl Marx (capital económico), Pierre Bourdieu (capital simbólico) y Robert Putnam (capital social). Desde esta perspectiva, se entiende que la capital turística este sentido, la capital turística es el legado económico, social y simbólico proporcionado por factores técnicos, científicos, informativos, corporativos y públicos con participación de las organizaciones y comunidades gubernamentales y no gubernamentales, se materializó y desarrollado en los lugares adecuados para el turismo con articulada en otros lugares. Sin embargo, fue necesario utilizar el enfoque metodológico de análisis cualitativo y crítico para el proceso de reflexión de la discusión aquí puesto. Por lo tanto, el concepto de capital turística se presenta como otro aporte teórico para el estudio y la investigación para una mejor comprensión del fenómeno turístico en la escena contemporánea.

Palabras clave: Capital turístico; Capital económico; Capital simbólico; Capital social.

\section{Introdução}

O artigo é pautado em abordagem crítica sobre os fatos e processos, pois, ao mesmo tempo em que os discursos de ordem pública conferem ao turismo um tipo de desenvolvimento preconizado pelos documentos oficiais dos governos e das diversas instâncias de governança (federal, estadual e municipal) pelos veículos de comunicação de toda natureza e, em especial, no imaginário social das populações anfitriãs e visitante que aferem ao turismo uma série de benesses como oportunidades de ascensão social e crescimento econômico, por exemplo.

O turismo, além de ser uma atividade econômica, também é um fenômeno sociocultural e, como tal, é construído, historicamente, pela ação dos sujeitos sociais e agentes econômicos por meio de processos capitalistas que evoluem no decorrer dos anos, sofrendo as intempéries globais e influenciando as particularidades locais. Portanto, as relações capitalistas produzidas na sociedade são também de natureza dialética, como são os discursos teóricos e a realidade empírica do turismo.

Com o crescimento e a consolidação da sociedade capitalista pós-guerra, fundamentados pela formação da sociedade industrial que possui raízes no continente europeu no século XVIII, difundiram-se diversos processos que culminaram em conquistas do ponto de vista social nos séculos subsequentes, dentre elas: o tempo dedicado às atividades de lazer e a realização de viagens turísticas. Nesse contexto, os países periféricos não ficaram à margem desse processo, 
iniciando, mesmo que de forma embrionária, o desenvolvimento da atividade turística nos moldes capitalistas de produção e reprodução do capital, a qual se propagou por meio do segmento de turismo de sol e praia em escala global, principalmente em países litorâneos.

Nessa nova atmosfera alimentada pelo avanço do capitalismo foi construída, paulatinamente, a ideia de que o turismo internacional significaria a geração de riquezas, trabalho e negócios, crescimento econômico e desenvolvimento social para as localidades receptoras (sobretudo, nos países subdesenvolvidos ou em desenvolvimento), com destaque para as divisas econômicas geradas pelo capital estrangeiro reproduzido em ambientes litorâneos e responsável pela exploração da atividade turística voltada para o consumo de bens e serviços com fins turísticos.

Esse artigo levanta a discussão sobre um novo conceito no campo do turismo, ou seja, a concepção conceitual de capital turístico. Esse conceito, em construção, baseia-se nas teorias sociais a respeito do capital econômico (Karl Marx), capital simbólico (Pierre Bourdieu) e capital social (Robert Putnam).

O método de pesquisa concebido nesse trabalho foi de natureza qualitativa e análise crítica dos fundamentos teórico-metodológicos das teorias sociais, em que as pesquisas documental e bibliográfica foram de suma importância para a concepção desse novo conceito no campo do saber turístico, denominado nesse artigo de: "capital turístico".

\section{As Teorias Sociais de Marx, Bourdieu e Putnam: fundamentos do conceito de capital Turístico}

Essa discussão é resultado dos estudos a respeito do conceito de capital econômico teorizado por Karl Marx, sob o ponto de vista da abordagem em relação ao capital simbólico de Pierre Bourdieu e, a visão de Robert Putnam sobre o capital social. Tal debate levará à construção de um novo conceito, o de capital turístico, bem como à complexidade teórico-metodológica no campo científico.

O conceito de capital foi difundido em proporções globais a partir da teoria marxista (estudos teóricos sobre a sociedade, economia e política), em que o sociólogo e filósofo alemão Karl Marx, juntamente com Friedrich Engels, da corrente teórico-filosófica denominada de 
socialismo científico, comumente reconhecida como marxismo, discorreram sobre o papel dessa conceituação na sociedade moderna.

O pensamento de Karl Marx se materializou por meio de importantes reflexões teóricas como: a transição gradual para o comunismo, ditadura do proletariado, materialismo histórico, materialismo dialético, socialismo científico, modo de produção, mais-valia, luta de classes, teoria marxista da ideologia, teoria marxista da alienação, fetichismo da mercadoria, dentre outros conceitos que contribuíram para a formação do pensamento moderno e das teorias clássicas das ciências sociais e humanas.

A partir da teoria crítica, Karl Marx defende que é preciso unir o pensamento a uma prática real, revolucionária, o que ele denominou e práxis (relação teoria-prática). Esse pensamento impactou diretamente as teorias modernas das relações sociais e o campo das humanidades, inspirando a construção de novas teorias e métodos de análise com base na práxis.

O Capital: crítica da economia política, a obra máxima de Karl Marx, revolucionou o mundo e a forma de pensar a sociedade, a política e a economia. Essa obra foi desenvolvida com base em estudos e pesquisas sobre a história, sociologia, economia, religião e política, inspirada nesse contexto histórico e sociocultural, mais precisamente, na segunda metade do século XIX, durante a temporada em Londres. O Capital apresenta-se como uma análise estrutural, um estudo longitudinal, em que a sociedade é vista como uma instância onde ocorre a troca de mercadorias e a produção do capital e das relações de poder.

Marx teorizou no período compreendido entre 1867 a 1894 (FERACINE, 2011) um sistema de ideias de forma profunda e substancial a respeito do processo de produção do capital durante os primórdios da estruturação moderna do sistema capitalista ou modo de produção capitalista, cujo capital é tido como origem e o fim desse processo. Nesse sentido, Marx por meio do método materialismo-dialético-histórico, pensa a sociedade pela via da estrutura econômica, ou seja, pelo modo de produção vigente.

Ao questionar e não concordar com os efeitos perversos do modo de produção alicerçado pelo capital, Marx se depara com problemas de ordem social e política naquele contexto vivido, século XIX, cujo pano de fundo era o cenário europeu, sobretudo o contexto da Inglaterra. Para ele, o "homem é dominado por seus produtos" e não o contrário, uma vez que, que esse homem também é meio de produção e refém e produto do modo de produção moderno, em suma, o homem (trabalhador) também é capital. 
O ideário da Nova Divisão Internacional do Trabalho apontado por Marx, baseia-se no sistema em que os países menos desenvolvidos (colônias e ex-colônias - Novo Mundo) se especializaram na produção da matéria-prima para suprir as necessidades emergentes de países centrais como a Inglaterra (Velho Mundo) que se encontrava em pleno desenvolvimento industrial e de produção e reprodução do capital. Esse fenômeno capitalista denominado de "industrialização" marca a passagem do domínio do capital mercantil para o capital industrial da era moderna.

No célebre: "O Manifesto Comunista", Marx e Engels (1998) conclamam a sociedade, os trabalhadores e intelectuais de todo o mundo, para discutir e refletir sobre a luta de classes e as contradições sociais efervescentes marcantes do século XVIII. Nesse sentido, o Manisfesto, afirma-se como importante documento para a compreensão do império das relações mercantis em âmbito global, o domínio do capital e, consequentemente, a luta de classes nos dias contemporâneos, revestidos de nova forma e conteúdo.

A teoria sobre a organização do capital, sistematizada teoricamente por Marx, explica uma série de acontecimentos históricos vivenciados na transição do período feudal para a Idade Moderna, período de intensificação da luta de classes (burguesia - proletariado) e da dominação do modo de produção capitalista sob a sociedade, focada no trabalho operário e no crescimento do próprio capital privado. Para Marx e Engels (1998, p. 29) a "condição essencial para a existência e para o poder da classe burguesa é a formação e o crescimento de capital. A condição para o capital é o trabalho assalariado".

O trabalho na concepção de Marx (1973) também se transforma em mercadoria. A mercadoria possui valor de uso (qualidade do produto fruto do trabalho concreto) e de troca (quantidade da mercadoria, equivalente a dinheiro, fruto do trabalho abstrato). $\mathrm{O}$ que determina a grandeza do valor é o tempo de trabalho, que é socialmente necessário para a produção de um valor de uso.

Para Marx (1973) o mercado é o espaço onde ocorre a troca de mercadorias, sendo que o valor da mercadoria envolve salários, estrutura da maquinaria, matéria-prima e o trabalho empregado pelo operário. O dinheiro aparece como expressão e fonte da mercadoria, componente importante para a relação de produção e consumo do capital.

A produção não é apenas imediatamente consumo e o consumo não é apenas imediatamente produção, a produção não é apenas meio para o consumo e o consumo não é apenas o objetivo 
da produção (...) mas também, tanto a produção quanto o consumo (...) criam o outro, complementando-se e criando-se enquanto o outro (MARX, 1973).

A relação dialética entre produção e consumo é pertinente ao modo de produção capitalista, um elemento sui generis para a compreensão das nuances do próprio capital. Com base no sistema de ideias organizado por Marx, sobretudo, no estudo profundo sobre as raízes e desdobramentos do capital econômico, afirma-se que o capitalismo (propriedade privada dos meios de produção) surge quando o capital se apropria da produção, em que esse capital é centralizado por meio de monopólios, o que incrementa e intensifica as desigualdades sociais no mundo contemporâneo.

O turismo também surge como fenômeno social e atividade econômica com base nas relações capitalistas de poder e distinção social, ainda no século XVIII, considerado como uma atividade econômica moderna e voltada para o domínio do lazer, fora do contexto do trabalho, mas imbricado pela produção capitalista da sociedade moderna. Na sociedade contemporânea, esse cenário se modificou, uma vez que também existem momentos e atividades de lazer no âmbito produtivo e nas ocasiões dedicadas ao ócio.

Nesse sentido, o capital teorizado por Marx é um dos princípios fundantes do capital turístico aqui apresentado, uma vez que, o turismo é uma das principais atividades produtivas no campo econômico na contemporaneidade e concentrador de riquezas, incluindo e excluindo segmentos da sociedade, quer seja pelo processo de turistificação do espaço geográfico, quer seja por meio da dinâmica de construção de territórios turísticos, ou por ambos os fatores.

Segundo Marx (2014, p. 183) “o movimento do capital não tem limites”, o que significa dizer que o proprietário do dinheiro, torna-se capitalista, pois o dinheiro sai do bolso e retorna para ele em meio ao processo de produção capitalista e também de produção social. Para Marx (2014, p. 331) a "natureza do capital é a mesma, não importa o grau de desenvolvimento das forças”. Nesse sentido, o capital é a força motriz da produção e reprodução do próprio capital, seja pela circulação de mercadorias diversas, ora pela movimentação do capital no contexto de produção capitalista globalizado e repleto de contradições inerentes a esse sistema econômico de produção do capital.

Marx \& Engels (1998, p. 34) afirmam que o “capital não é, portanto, um poder pessoal, mas um poder social". Sendo assim, o turismo como uma das expressões modernas do sistema capitalista, afere ao consumidor (turista) à condição efêmera de poder social, uma vez que, 
necessariamente, o sujeito além de possuir o capital financeiro para a realização da viagem, também se reveste desse personagem denominado de turista, cujo interesse é se distinguir das demais pessoas por meio da condição econômica materializada com o advento da viagem (destino, equipamentos turísticos utilizados, lugares visitados, produtos e serviços consumidos...). Contudo, o interesse no enriquecimento cultural e na vivência de novas experiências fora da situação real do cotidiano também são elementos intrínsecos ao fenômeno turístico, à arte de viajar.

Na recente construção e consolidação da sociedade capitalista, a classe dominante (burgueses, capitalistas, empresários etc.), ou seja, os detentores do capital, do poder social e operadores das estruturas de poder e dominação existentes, constituem nos dias vigentes, o poder hegemônico que é resultado do processo de produção de capital e marca do capitalista contemporâneo.

Segundo Marx \& Engels (1998, p. 33-34) ser um capitalista é "ter não só uma condição puramente pessoal mas uma condição social na produção. $\mathrm{O}$ capital é um produto coletivo e só pela ação unida de muitos membros e ainda, como último recurso, é só pela ação unida de todos os membros da sociedade que ele pode ser movimentado".

O “capital é, portanto, não um poder pessoal, mas um poder social” (MARX \& ENGELS, 1998, p. 34). Nesse sentido, o capital como poder social produzido pelas relações produtivas coletivas, apresenta-se como importante conteúdo para a compreensão do capital no campo do simbólico e do social, que contribuirão para a construção do conceito de capital turístico.

O sociólogo francês Pierre Bourdieu, pensador do século XX, ao teorizar sobre o sentido de campo, dialoga e se aproxima da ideia de esferas defendidas por Max Weber e, com o conceito de classe social de Karl Marx. Para Bourdieu, o universo social deve ser compreendido sob a perspectiva de três conceitos fundamentais: campo, habitus e capital.

Em a "Economia das trocas simbólicas", Bourdieu (2009) faz uma exaustiva reflexão sobre a realidade social, em que o estudo da simbolização por meio de bases sociais, com ênfase na teoria da cultura e da ideologia.

O sistema de representações simbólicas, que compõem o campo da cultura, possui duas vertentes ideológicas tradicionais. A primeira considera a cultura como extensão de todos os sistemas simbólicos (arte, mito, linguagem etc.), um diálogo entre os significados dos signos e 
do mundo. A segunda considera a cultura e os sistemas simbólicos em seu conjunto como um instrumento de poder - legitimação da ordem vigente (BOURDIEU, 2009).

Para Bourdieu (2009) ambas as concepções sobre o sistema de representações simbólicas são tendências que reforçam a delimitação de um espaço para o cultivo de experiências baseadas na vontade do agente social.

O esforço intelectual de Bourdieu (2009) é aliar o reconhecimento da organização inerente ao campo simbólico à percepção de sua função ideológica e política, para legitimar uma ordem arbitrária em que se funda o sistema de dominação vigente, que analisa também a estrutura real das relações sociais.

No livro "Os usos sociais da ciência - por uma sociologia clínica do campo científico", Bourdieu discorre

[...] o mundo da ciência, como o mundo econômico, conhece relações de força, fenômenos de concentração do capital e do poder ou mesmo de monopólio, relações sociais de dominação que implicam uma apropriação dos meios de produção e de reprodução, conhece também lutas que, em parte, têm móvel o controle dos meios de produção e reprodução específicos, próprios do subuniverso considerado (BOURDIEU, 2004, p. 34)

Nesse contexto, a ciência é considerada um campo (lugares de relações de força que sugerem tendências, cenários e probabilidades objetivas) segundo os estudos bourdienianos. A noção de habitus usada por Bourdieu (2004, p. 28) diz respeito às "maneiras de ser permanentes, duráveis, que podem, em particular, levá-los a resistir, a opor-se às forças do campo". Para o autor, qualquer que seja o campo, ele é objeto de luta, quer seja na representação, quer seja na realidade.

Todavia, nessa análise se leva em consideração o conceito de capital simbólico e as implicações na construção do capital turístico. Assim como a contribuição de Marx em relação ao capital econômico, o capital simbólico produzido pelo capital cultural de Bourdieu, também traduz sentido e significado para o melhor entendimento a respeito do capital turístico aqui apresentado como categoria conceitual do campo do turismo.

O capital cultural possibilita ganhos em todos os jogos da vida em sociedade, pois à medida que esse capital cresce amparado por condicionantes de eficiência, ele também determina o sucesso e a posição social dos agentes em dado espaço social. A posição de determinado agente no espaço social poderá ser definida de acordo com a condição que ocupa em 
diferentes campos e situações, poderá ser por meio do capital econômico, do capital cultural, do capital social ou do capital simbólico, bases para a formação de um campo social (BOURDIEU, 2010).

O capital simbólico está relacionado a prestígio, reputação, fama e posição social, uma forma percebida e reconhecida, legitimamente, nas diferentes modalidades de capital. Segundo Bourdieu, é o campo econômico que tende impor a estrutura aos demais campos do espaço social.

Ao falar sobre o poder simbólico, Bourdieu (2010, p. 114-145) retoma o conceito de distinção, que para ele é a "diferença inscrita na própria estrutura do espaço social quando percebida segundo as categorias apropriadas a essa estrutura”. Assim sendo, o capital simbólico (compreendido como distinção), é o capital em qualquer que seja a espécie e forma de atuação no espaço social.

De acordo com Bourdieu (2010, p. 153), o espaço social é um espaço multidimensional, que consiste em

[...] conjunto aberto de campos relativamente autônomos, quer dizer, subordinados quanto ao seu funcionamento e às suas transformações, de modo mais ou menos firme e mais ou menos direto ao campo de produção econômica: no interior de cada um dos subespaços, os ocupantes das posições dominantes e os ocupantes das posições dominadas estão ininterruptamente envolvidos em lutas de diferentes formas (sem por isso se constituírem necessariamente em grupos antagonistas).

O capital simbólico é incorporado pelo próprio capital simbólico, não apenas pelo fato da autonomia real do campo de produção simbólica não impede que ele permaneça dominado, no funcionamento, e pelos constrangimentos que dominam o campo social, mas, sobretudo, devido às relações de força objetivas inclinarem-se a reproduzir-se nas relações de força simbólicas, na percepção do mundo social que possibilitam a garantia da permanência dessas relações de força (Bourdieu, 2010).

Os títulos oficialmente aferidos aos atores ou agentes sociais, seja no domínio escolar, profissional, militar, religioso ou nobiliário são expressões reais do capital simbólico que identificam posições sociais e solidificam a distinção social no âmago da sociedade (BOURDIEU, 2013).

Tais títulos são materializados como um direito adquirido, capital simbólico institucionalizado pelas forças de poder, legalmente constituídas, não são somente legítimos, 
mas são ganhos no campo do simbólico e da distinção social, valorada cada vez mais na sociedade contemporânea.

Sobrenome de famílias, títulos, posição social, ascensão profissional e prêmios são símbolos de distinção social, que segundo Bourdieu (2010 p. 149) é a "raridade simbólica do título no espaço dos nomes de profissão que tende a comandar a retribuição da profissão" (e não a relação entre a oferta e a procura de certa forma de trabalho) segue-se daqui que a retribuição do título tende a tornar-se autônoma em relação a retribuição do trabalho.

De acordo com o autor, a mesma função profissional, o desempenho do mesmo trabalho, pode aferir remunerações diferenciadas, conforme o título ou status social daquele que a exerce, sendo o título uma instituição poderosa como a própria língua. Para o autor, todo o campo é uma arena de lutas (BOURDIEU, 2010). Nessa perspectiva, a força simbólica dos atores e agentes envolvidos em uma luta nunca é essencialmente independente da posição de cada envolvido no jogo, mesmo que o poder simbólico, propriamente dito, da nomeação e da distinção social constitua uma força autônoma (relativa) em relação às demais expressões de força social.

O poder simbólico de cada agente depende da posição social ocupada no espaço e do capital simbólico acumulado, sendo um reflexo do status social no campo das representações sociais pelas vias do simbólico. O poder simbólico é aquele que lhe está sujeito a dar àquele que o exerce, um crédito com que ele o credita, construindo uma relação estreita e de plena confiança (BOURDIEU, 2010). Esse poder somente existe devido àquele que lhe está sujeito, subordinado, crê que ele é real e concreto e, portanto, existe.

O capital simbólico é constituído de forma acumulativa pelas vias da representação social, sendo uma derivação do capital cultural e alicerçado pelo capital econômico, a mais fina expressão da distinção social entre dominados e dominantes, uma apologia à sociedade do status e da diferenciação de classes pelo viés do arcabouço econômico e do poder simbólico.

O turismo se reveste do capital simbólico e revela-se por meio da distinção social entre turistas e não turistas (residentes ou trabalhadores do setor turístico ou pessoas que não possuem as condições necessárias à realização de uma viagem para fins de lazer). Nesse sentido, o turista é o sujeito, o protagonista do fazer turístico, em que todo o sistema produtivo se volta para atender as expectativas e desejos. O turista assume posição social de destaque, assim como os demais consumidores de bens e serviços no campo econômico. 
O capital simbólico imprime ao turista a designação de agente principal da atividade turística, o que encadeia uma série de cuidados junto ao espaço geográfico visitado e aos diversos campos envolvidos (econômico, social, político, ecológico, cultural e jurídico), para garantir a integridade, segurança, bem-estar e hospitalidade durante toda a experiência turística desse ator social denominado de turista.

Apesar de se encontrar no papel ou na condição de turista, esse ator busca a diferenciação social por meio de práticas concretas de vivência turística, sendo que o capital econômico e a posição social que ocupa contribuem de forma decisiva com o processo de distinção social, almejado pelo turista que quer se diferenciar dos demais, ora pela busca de destinos turísticos exóticos e pouco visitados, ora pela procura por mercados de luxo e elitizados, o que afere ao turista o aspecto de personalização dos serviços e/ou exclusividade.

Adquirir produtos e serviços exclusivos ou não acessíveis à maioria dos turistas é sinônimo de status e posição social privilegiada. O poder aliado ao capital cultural e ao capital econômico proporciona a esse tipo de turista, não apenas a impressão, mas a certeza que ele é diferenciado e que merece tratamento especial, reflexo do capital simbólico no campo do turismo.

O cientista político e professor norte-americano, com atuação na Universidade Harvard, Robert Putnam, é um dos principais pesquisadores contemporâneos a teorizar sobre o capital social. Na visão desse autor, o capital social se refere às práticas sociais, normas e relações de confiança que existe entre cidadãos de uma determinada sociedade.

A confiança é um componente básico do capital social, uma vez que, promove cooperação. "Quanto mais elevado o nível de confiança numa comunidade, maior a probabilidade de haver cooperação. E a própria cooperação gera confiança" (PUTNAM, 2006, p. 180).

Segundo o pensamento de Putnam sobre o capital social, a confiança implica uma previsão de comportamento dos atores, de forma independente. A relação somente é estabelecida no que se confia (pessoas, entidades, organizações, projetos, ideias). A capacidade, a disposição, as alternativas e as consequências desses atores podem passar ou não confiança, sendo resultado de um convívio direto com esses atores.

A teoria sustentada pelos estudos de Putnam em relação ao capital social defende que a interação pessoal é um meio legítimo e eficaz para obter informações no que diz respeito à confiabilidade dos demais atores envolvidos nesse processo. O capital social também ajuda a 
entender melhor sobre o porquê da corporificação em sistemas sociais horizontais de participação cívica, favorece o desempenho do governo e da economia e não o oposto disso: sociedade forte, economia forte; sociedade forte, Estado forte (PUTNAM, 2006).

Deve-se pontuar que os estudos empíricos de Putnam sobre a relação comunidade e democracia, tiveram como pano de fundo a experiência da Itália Moderna. Desse modo, o autor afirma que os estoques de capital social (confiança, reciprocidade, normas e sistemas de participação, civismo, bem estar social coletivo, cooperação etc.) são elementos que definem uma comunidade ou sociedade cívica que tendem a ser cumulativos e a se reforçarem de forma mútua por meio de diferentes instituições e relações interpessoais.

Sendo as instituições importantes atores sociais para a construção do capital social de dada sociedade ou comunidade, Putnam comenta que as "instituições de cunho cooperativo requerem aptidões e confiança interpessoais, mas essas aptidões e essa confiança são igualmente inculcadas e reforçadas pela colaboração organizada". "As normas e os sistemas de participação cívica contribuem para a prosperidade econômica e são por sua vez reforçados por essa prosperidade" (PUTNAM, 2006, p. 190).

O capital social não é construído de maneira fácil, mas é um condicionante indispensável para o funcionamento das democracias existentes em todos os continentes do mundo e, especialmente, para as sociedades que vislumbram se tornarem democráticas.

Com base no conceito de capital social de Putnam, pode-se dizer que no contexto contemporâneo os atores sociais como: cooperativas, conselhos, associações, sindicatos e demais organizações coletivas, que representam a sociedade (Estado, sociedade civil e agentes do mercado), assumiram um papel histórico, social, político e cívico de grande relevância para a construção e o equilíbrio da vida em sociedade segundo os princípios da coletividade, da reciprocidade e da confiança.

As diversas abordagens sobre o capital, sobretudo nas dimensões econômica, simbólica e social de acordo com os pensadores das ciências sociais aqui contemplados são imprescindíveis para a compreensão e o desenvolvimento conceitual das bases teóricas do capital turístico, que se revela como importante contribuição para o desenvolvimento de estudos e pesquisas a respeito do fenômeno turístico contemporâneo em diferentes realidades e que se traduz por meio de uma práxis da dialética do mundo real e da abstração do poder simbólico. 
Marx dedicou parte da vida à teorização e sistematização dos elementos que corporificaram o capital, que se traduz como uma análise complexa e ampla do modo de produção capitalista, bem como a gênese histórica e as contradições imanentes da dinâmica do próprio capital.

O conceito de capital simbólico aprofunda-se a partir dos estudos de Bourdieu sobre capital cultural (diplomas, nível de conhecimento universal, etiqueta e boas maneiras) é utilizado para se distinguir do capital econômico e do capital social (rede de relações sociais). $\mathrm{Na}$ Distinção, ele expõe duas ideias centrais e originais. De um lado, as relações de poder como categoria de dominação é analisada pela metáfora do capital cultural no qual se apoia o princípio de reprodução social. De outro, o entrecruzamento das relações de poder com as várias formas de ações organizadas favorece a capacidade dos indivíduos para elaborar estratégias que, todavia, não ultrapassam as relações de desigualdades sociais (VASCONCELLOS, 2002).

Bourdieu também foi um dos estudiosos a se dedicar sobre a teoria do campo científico e ao conceito de capital social, que anos depois foi retomado por Putnam para explicar as tradições cívicas e a experiência da Itália moderna. No quadro 1 serão apresentadas as conexões entre o turismo e as teorias sociais de Marx, Bourdieu e Putnam, que são os fundamentos teóricos para a construção do conceito de capital turístico. 


\begin{tabular}{|l|l|l|l|}
\hline \multicolumn{3}{|c|}{ Quadro 1: O cerne das teorias sociais de Marx, Bourdieu e Putnam e as conexões com o turismo } \\
\hline & \multicolumn{2}{|c|}{ DIMENSÕES SOCIOLÓGICAS E O TURISMO } \\
\hline
\end{tabular}

Fonte: TAVEIRA, M. S., 2015. 
Com base nos elementos conceituais expostos no quadro sobre as teorias de Marx, Bourdieu e Putnam, imprime-se o conceito de capital turístico para uma melhor compreensão do fenômeno turístico e de aspectos econômicos, simbólicos e sociais.

Portanto, o capital turístico é o legado econômico, social e simbólico proporcionado por fatores técnicos, científicos, informacionais, empresariais e públicos, com participação de organizações governamentais e não governamentais e das comunidades, materializado e desenvolvido em lugares apropriados pelo turismo articulados com os outros lugares (TAVEIRA, 2015, p. 233).

O capital turístico é sustentado pelo capital econômico por meio dos agentes de mercado que produzem e reproduzem o capital por meio da apropriação do espaço para o desenvolvimento do turismo como atividade econômica, produtiva, que oportuniza a geração de riquezas financeiras e de negócios empresariais voltados a esse setor. Nesse domínio, o capital de origem privada é o principal motor que impulsiona a economia do turismo e acelera o processo de turistificação no espaço selecionado pelo capital.

O capital simbólico que faz parte do mundo social interfere diretamente no fenômeno turístico, sendo componente fundamental na condição de status social aferida aos turistas, atribuindo a esse uma conotação de diferenciação e destaque perante aos demais atores da sociedade. O poder simbólico se faz presente nesse capital por meio das mais variadas esferas de poder, no mundo do trabalho, na relação hóspede-anfitrião (cultura da hospitalidade), na dinâmica dos agentes produtores do espaço e na diversidade das experiências turísticas, especialmente nos destinos turistificados. Os elementos concretos e abstratos inerentes ao capital simbólico são também atributos significativos na construção do capital turístico, uma vez que, a distinção social e o poder simbólico são incorporados pelo turismo na sua essência e operacionalização.

O capital social representado pelas normas, instituições e sistemas organizacionais, também é um conceito fundante para o entendimento do capital turístico, uma vez que, o turismo é um fenômeno social e uma atividade econômica multifacetada. Sendo assim, um complexo de ações dos campos econômico, institucional e jurídico funcionam como alicerce indispensável ao desenvolvimento da atividade econômica. A infraestrutura que serve ao turismo, os investimentos de ordem pública, o sistema de financiamento e de crédito oficial dos governos 
em todas as esferas de poder, a concepção de governança das regiões e destinos turísticos, além da participação ativa de representações do terceiro setor (ONGs, associações, cooperativas, instituições de ensino, conselhos comunitários e setoriais, sindicatos e muitas outras) contribuem, efetivamente, para o bom desempenho institucional do setor turístico.

As políticas públicas são implementadas em diversos segmentos da atividade turística, desde a viabilização de ações infraestruturais de ordem jurídica e de capacitação de capital humano, necessárias ao desenvolvimento do turismo e fundamentais para a construção do capital turístico.

Diante das evidências teóricas e empíricas é inegável a existência de um capital turístico, que ganha forma e conteúdo de acordo com a natureza e o nível de desenvolvimento da atividade turística em dado espaço apropriado para esse fim. O capital turístico é a materialização de uma miscelânea de fatores de ordem pública, privada, jurídica e simbólica, que reflete os efeitos de uma construção histórica, politica, econômica, social e cultural dos elementos que compõem a própria estrutura da sociedade contemporânea.

\section{Considerações Finais}

O aparato teórico produzido nesse artigo tem base nas teorias de Marx (capital econômico), Bourdieu (capital simbólico) e Putnam (capital social) para produção de um novo conceito científico no campo do turismo, o de capital turístico. O conceito de capital turístico é apresentado como um legado econômico, social e simbólico proporcionado por fatores técnicos, científicos, informacionais, empresariais e públicos, com participação de organizações governamentais e não governamentais e de comunidades, materializado e desenvolvido em lugares apropriados pelo turismo e articulados com outros lugares.

O capital turístico é alimentado pelo capital econômico por meio dos mais variados agentes de mercado que produzem e reproduzem o capital em espaços apropriados para o desenvolvimento do turismo como atividade econômica e produtiva, que oportuniza a geração de riquezas financeiras e de negócios empresariais voltados à atividade. Nesse domínio, o capital privado é o principal motor que movimenta a economia do turismo e intensifica ainda mais o processo de turistificação no espaço selecionado pelo capital. 
O capital simbólico visto como especifico do mundo social interfere, diretamente, no fenômeno turístico, constitui-se como componente fundamental na condição de status social aferida aos turistas, atribui a esse a conotação de diferenciação e destaque perante aos demais atores da sociedade. O poder simbólico se faz presente nas variadas esferas de poder, no mundo do trabalho, na relação hóspede-anfitrião (cultura da hospitalidade), na dinâmica dos agentes produtores do espaço e, na diversidade das experiências turísticas, especialmente nos destinos turistificados ou em processo de turistificação, além de fazer parte do capital simbólico.

O capital social é representado pelas normas, instituições e sistemas organizacionais, concebido com um dos conceitos fundantes do capital turístico, uma vez que, o turismo é uma atividade econômica, fenômeno social e imagem que se apropria de ícones. Esse complexo de ações nos campos econômico, institucional e jurídico, funciona como alicerce indispensável ao desenvolvimento da atividade turística.

Portanto, o conceito de capital turístico está em processo de construção teórica e aplicações empíricas, o que é pertinente, pois, trata-se de um conceito novo que contribuirá para futuras análises a respeito do fenômeno turístico contemporâneo em diferentes realidades e cenários multifacetados. A concepção desse conceito é uma provocação teórico-metodológica para realização de outros estudos e comprovações científicas da pertinência e implicações no campo do saber turístico.

\section{Referências}

BOURDIEU, Pierre. A Distinção: crítica social do julgamento. - 2 ed. - Porto Alegre: Zouk, 2013. . O Poder Simbólico. - 14 ed. - Rio de Janeiro: Bertrand Brasil, 2010. . A economia das trocas simbólicas. - 6 ed. - São Paulo: Perspectiva, 2009.

. Os usos sociais da ciência: por uma sociologia clínica do campo científico. São Paulo: Editora UNESP, 2004.

FERACINE, Luiz. Karl Marx ou a Sociologia do Marxismo. São Paulo: Editora Escala, 2011.

MARX, Karl. O Capital - crítica da economia política: Livro I. - 33 ed. - Rio de Janeiro: Civilização Brasileira, 2014. . Contribuição à crítica da economia política. Lisboa: Estampa, 1973.

MARX, Karl e; ENGELS, Friedrich. O manifesto comunista. Rio de Janeiro: Paz e Terra, 1998. 
PUTNAM, Robert D. Comunidade e Democracia: a experiência da Itália moderna. - 5 ed. - Rio de Janeiro: Editora FGV, 2006.

VASCONCELLOS, Maria Drosila. Pierre Bourdieu: a herança sociológica. Educação e Sociedade. Campinas, SP: CEDES, XXIII (78), p.77-87. 2002.

TAVEIRA, M. S. Turismo e comunidades de praia: São Miguel do Gostoso no caminho do mar e na direção dos ventos. Tese de Doutorado (Programa de Pós Graduação em Ciências Sociais), Natal: UFRN, 2015.

Recebido em: 09/12/2015 (1 ${ }^{\mathrm{a}}$ versão) $27 / 04 / 2016$ ( $2^{\mathrm{a}}$ versão)

Aprovado em: 28/04/2016 